\title{
Influences on the Adoption of Mobile Learning in Saudi Women Teachers in Higher Education
}

\author{
http://dx.doi.org/10.3991/ijim.v9i2.4411 \\ L.A. Alfarani \\ King Abdulaziz University, Jeddah, Saudi Arabia \\ University of Leeds, Leeds, UK
}

\begin{abstract}
Although mobile devices are ubiquitous on university campuses, teacher-readiness for mobile learning has yet to be fully explored in the non-western nations. This study shows that two main factors affect the adoption and use of m-learning among female teachers within a university in Saudi Arabia-resistance to change and perceived social culture. These determinants of the current use and intention to use of m-learning were revealed through the analysis of an online questionnaire completed by 165 female faculty members. This study reveals several important issues for $\mathbf{m}$ learning research and practice. The results further extend the body of knowledge in the field of m-learning, with the findings revealing that resistance to change and perceived social culture are significant determinants of the current use of and the intention to use m-learning.
\end{abstract}

Index Terms-Blended Learning, Mobile Learning, Technology adoption.

\section{INTRODUCTION}

Over the last decade, mobile learning (m-learning) has undergone rapid developments, and this has had a significant impact on the higher education (HE) sector [1]. These developments have led to the need to re-imagine and reconceptualize the role of teachers in the learning process, and to understand the impact of using m-learning in order to support student learning. The extant literature on $\mathrm{m}$ learning provides evidence that supports the effectiveness of mobile technology in learning and teaching [2], and this success is grounded in extending learning and teaching beyond the traditional teacher-led classroom; expanding the accessibility of learning opportunities; providing flexible learning materials that can be used at any time and place; generating new methods of technology-enhanced learning; allowing new modes of teaching; and encouraging students' active participation in their learning [3] [2] [4]. Furthermore, m-learning facilitates teachers' implementations of student-centered pedagogies that allow access to learning materials at any time and place, and this has been shown to improve students' learning outcomes [5].

The growth of mobile learning has largely depended on the participation of teachers and their belief in the possibilities that this technology offers for enhancing learning [6]. As teachers play an active role in successfully integrating technology into education, it is important to understand the factors that encourage or discourage their participation [7]. The primary purpose of this paper is to examine faculty perceptions about using m-learning in a blended-learning scenario, and in particular those relating to perceived social culture and technology.

\section{LITERATURE REVIEW}

\section{A. M-learning in Saudi Arabia}

M-learning is in an early phase of its implementation in the Kingdom of Saudi Arabia [8], with the decision to formally adopt M-learning in Saudi universities being a very recent one. A useful definition of m-learning is provided by the e-Learning Guild [9], An activity that allows individuals to be more productive when consuming, interacting, or creating information, mediated through a compact digital portable device that the individual carries on a regular basis and has reliable connectivity and fits in a pocket or purse. The number of students that use mobile devices as educational resources continues to rise sharply in Saudi Arabia [10] [8], yet the readiness of Saudi teachers to use m-learning to support students' learning has yet to be explored.

\section{B. The challenges of m-learning}

The advantages and opportunities offered by m-learning have created a new era in the information age. Although m-learning provides opportunities, there are a number of obstacles to its success, such as poor connectivity, small screen sizes, limited processing power and reduced input capabilities [11]. In addition, Messinger (2012) [12] has highlighted a number of barriers that limit the widespread adoption of mobile learning, including:

1. The distractions that mobile devices can create within a traditional classroom;

2. The lack of empirical evidence regarding their effective use in the classroom that could encourage teachers to exploit them in their own classrooms;

3 . The lack of effective models in m-learning for meeting the needs of the 21 st century learner; and

4. The resistance of teachers to educational innovations.

\section{RESEARCH QUESTIONS}

This paper is guided by two main research questions:

1. Is either perceived social culture or resistance to change a significant predictor of the current and future intention of female teachers in Saudi Arabia to use mobile learning?

2. Is there a statistically significant relationship between female faculty members' personal characteristics (including age and years of teaching experience) and their perceptions towards mobile learning?

\section{ReSEARCH Model AND Hypotheses}

Reference 13 created the Unified Theory of Acceptance and Use of Technology (UTAUT), which identified the 


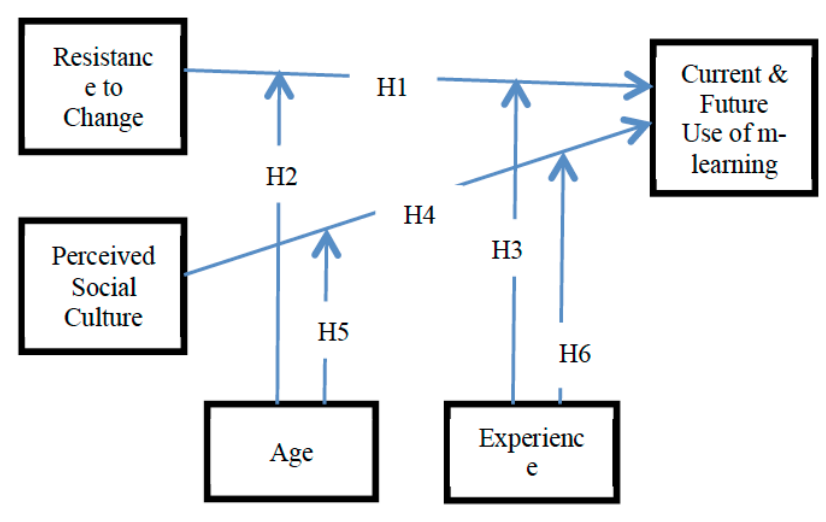

Figure 1. Research Model and Hypotheses

four constructs of performance expectancy, effort expectancy, social influence, and facilitating conditions as the primary factors that affect intention to use and usage behavior of technology. Reference 13 suggests that gender, age, experience, and voluntariness of use moderate the impact of these four key constructs on usage intention and behavior.

This study extends the UTAUT further in order to explore the addition of two new factors-resistance to change (RC), and perceived social culture (SC). Moreover, gender, age, and experience are hypothesized to be moderators of the effects of the four constructs (performance expectancy, effort expectancy, social influence, and facilitating conditions), as well as the two additional constructs on current use and intention to use. For the purpose of this short paper, only the additional constructs or factors are considered (resistance to change and perceived social culture), as this paper represents only a small part of a larger study. In addition, age and experience are the only moderators of these factors considered here.

\section{A. The current use of and the intention to use m-learning}

Numerous educational organizations in western region currently use mobile technology to support instruction and learning in HE [14]. An investigation of the relationship between the current use of mobile technology in mlearning and behavioral intentions to use this technology in the future might provide an insight into the likely adoption of mobile learning. In addition, teachers' negative attitudes and perceptions toward using mobile devices as learning tools will help in developing a deeper understanding of whether they are themselves a major obstacle for the deployment of m-learning in Saudi higher education.

\section{B. Resistance to Change}

Despite the global trend towards m-learning, some educators are still resistant to the idea of integrating this technology into their practice, mainly because of the various challenges it presents to them, with several studies indicating that resistance to change plays a key role in IT acceptance and adoption [15] [16]. Such resistance was therefore considered to be one of the critical factors for this study to explore. For instance, the size of the screen and interface on mobile devices were cited as technological obstacles; infrastructure, lack of support and institutional policies were cited as institutional obstacles; and finally, information overload, student and teacher skepticism and learning impact were cited as pedagogical obstacles.
This study thus is hypothesized that resistance to change [17] is the main hurdle for the adoption of a new style of teaching and learning among Saudi teachers, and the influence that resistance to change has on the current use and intention to use m-learning will here be moderated in relation to age and teaching experience. Consequently, this paper tests the following hypotheses:

Hypothesis 1: Resistance to change has a significant, negative effect on current use and intention to use mlearning.

Hypothesis 2: Resistance to change influences current use and intention to use m-learning more strongly for older than for younger teachers.

Hypothesis 3: Resistance to change influences teachers with over ten years experience more than teachers with less than ten years experience.

\section{Perceived Social culture}

It is widely accepted that the culture within a nation or an organization shapes individuals' perceptions of innovations that have a direct bearing on their lives [18]. Cultural differences in relation to perceptions towards types of technology are key factors for both the initial acceptance of these types of technology and for their future use [19] [18]. Saudi Arabia is a good example of a country with intellectual and cultural traditions relating to demographic variables (such as gender) that differ significantly from those seen in Western cultures, and which have a significant impact on the attitudes and subjective norms that influence behavioral intentions towards the use of technology [20].

In this paper, it is hypothesized that Saudi social norms might have a strong influence on faculty members' intentions to accept and use mobile devices in their academic setting, and both age and teaching experience moderate perceived social culture. Furthermore, Davis et al. (1989) [21] have noted that social norms might indirectly affect behavioral intentions, and they suggest further study in this area to provide a better understanding about the impact of social influences on user acceptance of technology. In addition, understanding the interaction of social and cultural differences with mobile learning technology is essential for designing and developing ways to successfully integrate it, broaden its user-base, and increase its acceptance. The influence of social culture on current use and intention to use m-learning will again be moderated by age and teaching experience, and the following hypotheses will be tested:

Hypothesis 4: Perceived social culture has a significant, negative effect on current use and intention to use mlearning.

Hypothesis 5: Perceived social culture influences current use and intention to use m-learning more strongly for older than for younger teachers.

Hypothesis 6: Perceived social culture influences current use and intention to use m-learning more strongly for teachers with over ten years experience than for teachers with less than ten years experience.

\section{RESEARCH METHODOLOGY}

\section{A. The survey instrument and sample}

An online questionnaire was designed to collect data that could be used to assess the research model. The scales 
used in the questionnaire were designed to be appropriate to the scope and context of the study. Four constructs were measured, based on five-point Likert-scales ranging from strongly disagree (1) to strongly agree (5). The measures for resistance to change (RC), perceived social culture (SC) and current use and intention to use m-learning in the future (CFU) are presented in Appendix A.

The female faculty members at King Abdulaziz University's (KAU) women's campus represent the target group for this study. The sample of 165 responses consists of a cross-section of staff from different age groups, with different amounts of teaching experience, a variety of academic positions (teacher assistants 26.6\%, lecturers $23.9 \%$, assistant professors $23 \%$, associate professors $16.4 \%$, and full professors $10.3 \%$ ), and from different departments and faculties in order to capture the range of teacher experiences and attitudes to using mobile devices in general. $98.2 \%$ of the teachers in the sample reported frequently using advanced mobile devices in social and/or professional life, such as iPads, iPhones, Android devices or other types of tablet or smart-phones, and Laptops.

Table II provides demographic information about the participants, who generally reported having advanced skills in using a number of features of mobile devices, thus presenting a positive attitude regarding the adoption of m-learning (see table II).

To explore the impact of the different variables on the attitudes towards using mobile technology in teaching and learning, survey respondents were divided into two age groups-over 40 years $(54.5 \%)$ and 40 years or under $(45.5 \%)$; as well as into two groups for years of teaching experience - ten years or less $(48.5 \%)$ and more than ten years $(51.5 \%)$.

\section{B. Data analysis and results}

The reliability of the factors was estimated by testing Cronbach's alpha using SPSS in order to evidence the consistency of items in each factor [22]. The initial analysis of data confirmed the reliability of RC and SC (Cronbach's alpha $=0.794$ and 0.809 , respectively). The average means of the constructs were then calculated and compared with the categories (current use and intention to use, age and teaching experience) in order to test the hypotheses. ANOVA and Chi-Square Tests were used to test the hypotheses and to calculate $\mathrm{P}$ values. The results are shown in table 3.

After this, statistical tests were conducted to examine the relationship of the two age groups (40 or less and over 40) with RC and SC. An examination of the Chi-square test and Pearson Correlation Coefficient enabled us to ascertain whether the patterns identified were significant. The results revealed a significant relationship $(\mathrm{p}=0.026)$. As table 3 shows, resistance to change has a significant effect on the current use of and the intention to use mlearning (Sig. $=0.005)$. Moreover, resistance to change influences current use and intention to use m-learning more strongly for older than for younger teachers. However, the effect of resistance to change on current use and intention to use was not significant for the most experienced group.

Similarly, the Sig. value was greater than 0.05 for testing the influences of social culture on current use and intention to use m-learning across both of the two teaching experience groups and the two age groups. Thus, Hypoth-
TABLE I.

CHARACTERISTICS OF THE RESPONDENTS

\begin{tabular}{|c|c|c|}
\hline Characteristic & Number & Percentage \\
\hline \multicolumn{3}{|c|}{ Age } \\
\hline Under 29 & 22 & $13.3 \%$ \\
\hline 30 and less than 40 & 53 & $32.1 \%$ \\
\hline 40 and less than 50 & 42 & $25.5 \%$ \\
\hline 50 and less than 60 & 41 & $24.8 \%$ \\
\hline Over 60 & 7 & $4.2 \%$ \\
\hline \multicolumn{3}{|c|}{ Teaching experience (TE) } \\
\hline Less than 5 years & 45 & $27.3 \%$ \\
\hline $5-9$ years & 35 & $21.2 \%$ \\
\hline $10-14$ years & 16 & $9.7 \%$ \\
\hline $15-19$ years & 18 & $10.9 \%$ \\
\hline 20 years or over & 51 & $30.9 \%$ \\
\hline \multicolumn{3}{|c|}{ Mobile devices using experience } \\
\hline To call and text & 156 & $94.5 \%$ \\
\hline $\begin{array}{l}\text { To download and play } \\
\text { games or applications } \\
\text { from the web }\end{array}$ & 97 & $58.8 \%$ \\
\hline To take photos & 145 & $87.9 \%$ \\
\hline $\begin{array}{l}\text { To send pictures or } \\
\text { videos to other people or } \\
\text { upload them online }\end{array}$ & 128 & $77.6 \%$ \\
\hline To send or receive email & 156 & $94.5 \%$ \\
\hline $\begin{array}{l}\text { To use social networking } \\
\text { software on the internet } \\
\text { (e.g. Facebook, Twitter, } \\
\text { etc) }\end{array}$ & 132 & $80 \%$ \\
\hline $\begin{array}{l}\text { To access information for } \\
\text { teaching and learning } \\
\text { purposes }\end{array}$ & 123 & $74.5 \%$ \\
\hline $\begin{array}{l}\text { To create/edit audio and } \\
\text { video }\end{array}$ & 43 & $26.1 \%$ \\
\hline
\end{tabular}

TABLE II.

SIG. VALUES FOR EACH HYPOTHESIS

\begin{tabular}{|l|l|l|l|l|}
\hline Hypotheses & Relationship & Sig. & $\begin{array}{c}\text { Testing } \\
\text { result }\end{array}$ & \multicolumn{1}{|c|}{ Pearson's $\boldsymbol{R}$} \\
\hline H1 & RC-CFU & 0.005 & Supported & Negative \\
\hline H2 & RC-Age & 0.006 & Supported & Older>younger \\
\hline H3 & RC-TE & 0.000 & Supported & $\begin{array}{l}\text { Experienced>less } \\
\text { experienced }\end{array}$ \\
\hline H4 & SC-CFU & 0.001 & Supported & Negative \\
\hline H5 & SC-Age & 0.132 & $\begin{array}{l}\text { Not sup- } \\
\text { ported }\end{array}$ & No difference \\
\hline H6 & SC-TE & 0.946 & $\begin{array}{l}\text { Not sup- } \\
\text { ported }\end{array}$ & No difference \\
\hline
\end{tabular}

eses 3, 5 and 6 were not supported. Unexpectedly, perceived social culture was found to be a stronger predictor of current use and intention to use m-learning among female Saudi teachers in higher education than resistance to change was.

\section{DISCUSSION AND CONCLUSION}

The primary purpose of this study was to investigate the influence of resistance to change and perceived social culture in MELO. Based on the UTAUT and prior studies, this study proposed an extended UTAUT to explore the factors affecting users' acceptance of m-learning by adding two constructs to the model: resistance to change and 


\section{SHORT PAPER}

\section{INFLUENCES ON THE AdOPTION OF MOBILE LEARNING IN SAUDI WOMEN TEACHERS IN HigHER EDUCATION}

perceived social culture. This study represents a pioneering attempt to apply the social culture construct to UTAUT in the context of m-learning, particularly within the Saudi higher education context. Although this study has produced numerous findings, only two extended constructs were analyzed and presented in this short paper.

Consistent with the findings of Huang, et al. (2012) the results of this study indicate that user-resistance to change had a significant, negative influence on the current use of and the intention to use m-learning. Data collected through this study supported the first three hypotheses (H1, H2 \& H3). It is worth noting that resistance to change was more significant for the older respondents than for the younger, as well as for the more experienced teachers than for the less experienced ones. Because the blending of m-learning in higher education is mainly dependent on educator acceptance of this type of learning, educator resistance to change clearly has an influence on learner outcomes. In student-centered learning environments, the blending and integration of technology into learning environments could play a key role in enhancing learning effectiveness and efficiency, with several studies indicating that there is a positive correlation between students' academic achievements and the deployment of technology into learning settings [23]. According to Cruz et al. (2012) [24], although participants (educators) perceived m-learning to have the capacity to enhance communication with students, as well as the resources and speed of feedback available to them, they identified technological, institutional, pedagogical and individual obstacles to the use of m-learning in academic contexts which had potentially negative influence on mobile learning acceptance. As educators have higher levels of resistance to change, it is possible that they could have less favorable current and future intentions to use mobile learning because they utilize mobile devices less.

Perceived social culture was shown to be a strong predictor of the current use and intention to use m-learning. It is therefore hypothesized that an individual with is strongly affected by Saudi social culture is less likely to adopt m-learning than an individual who is less affected by it. Very few studies mention the influence of social norms on the adoption and use of m-learning, and there is no extant research that examines the influence of culture on faculty acceptance of mobile learning technology in Saudi higher education environments. Al-Kahtani et al. (2006) [25] investigated the perceptions of female faculty members in Saudi Arabia regarding the use of the internet, although they did not investigate perceptions on the use of mlearning. They revealed that differences in perceptions towards the internet and its use vary strongly between different age groups and academic disciplines. Moreover, Al-Gahtani et al.'s (2007) [26] results indicated that culture is a significant moderator of technology acceptance amongst Saudi users, but this influence diminishes both with increasing age and increasing years of experience with computers.

As no research has been undertaken on social culture and m-learning in Arab countries, this acts as an inhibitor on the acceptance and use of m-learning, with female teachers having concerns regarding the integration of mobile devices into their teaching practices, the main one being about students misusing mobile devices in class, thus preventing them from benefitting from m-learning. The teachers indicated that this is a rising problem with using m-learning. Although the conservative attitudes of staff and students in Saudi universities regarding the use of mobile devices equipped with a camera negatively affects the use of mobile learning in class, the respondents were divided on this issue, with half 'agreeing' and the other half 'disagreeing'.

Thus, this study has successfully extended the applicability of the UTAUT in an m-learning context by adding two newly proposed constructs - resistance to change and perceived social culture. The findings of this study provide several important implications for m-learning research and practice.

Although mobile devices have become more accepted and popular in a variety of educational levels, m-learning remains in its infancy in Saudi higher education. The results of this study further extend the body of knowledge in the field of m-learning, with the findings revealing that resistance to change and perceived social culture are significant determinants of the current use of and the intention to use m-learning. Resistance to change is a negative influence on the acceptance of m-learning, but this influence diminishes with both increasing age and increasing years of teaching experience. However, although social culture has no significant influence on age groups and teaching experience, it does negatively affect the current use of and the intention to use m-learning.

\section{ACKNOWLEDGMENT}

I would like to express my sincere appreciation and gratitude to my supervisors, Dr. Maggie McPherson and Dr. Neil Morrris, from University of Leeds, for their guidance, patience, dedication, and encouragement.

\section{REFERENCES}

[1] Klassen, A., Eibrink-Lunzenauer, M., \& Gloggler, T. (2013). Requirements for mobile learning applications in higher education. InMultimedia (ISM), 2013 IEEE International Symposium on (pp. 492-497). IEEE. http://dx.doi.org/10.1109/ISM.2013.94

[2] Ktoridou, D., Gregoriou, G., \& Eteokleous, N. (2007). Viability of mobile devices integration in higher education: faculty perceptions and perspective. The 2007 International Conference on(pp. 5762). IEEE. http://dx.doi.org/10.1109/NGMAST.2007.4343401

[3] Guy, R. (Ed.). (2010). Mobile learning: Pilot projects and initiatives. Informing Science.

[4] Picek, R., \& Grcic, M. (2013). Evaluation of the Potential Use of $\mathrm{m}$-learning in Higher Education. In International Conference of INFORMATION TECHNOLOGY INTERFACES.

[5] Hu, L., and Webb, M. (2009). Integrating ICT to higher education in China: From the perspective of Activity Theory. Education and Information Technologies, 14(2), 143-161. http://dx.doi.org/10.1007/s10639-008-9084-6

[6] Tai, Y., \& Ting, Y. L. (2011). Adoption of mobile technology for language learning: Teacher attitudes and challenges. The JALT CALL Journal, 7(1), 3-18.

[7] Teo, T. (2009). Modelling technology acceptance in education: A study of pre-service teachers. Computers \& Education, 52(2), 302312. http://dx.doi.org/10.1016/j.compedu.2008.08.006

[8] Nassuora, A.B. (2012) Students Acceptance of Mobile Learning for Higher Education in Saudi Arabia. American Academic and Scholarly Research Journal, 4(2).

[9] "eLearning Guild," 2009, http://www.elearningguild.com/showFile.cfm?id=3673

[10] Al-Fahad, F. (2009) Students' attitudes and perceptions towards the effectiveness of mobile learning in king Saud University, Saudi Arabia. The Turkish Online Journal of Educational Technology, 8 (2), 111-119.

[11] Siau, K., Lim, E. P., \& Shen, Z. (2001). Mobile commerce: Promises, challenges and research agenda. Journal of Database Man- 


\section{SHORT PAPER}

\section{INFLUENCES ON THE AdOPTION OF MOBILE LEARNING IN SAUdi WOMEN TEACHERS IN Higher EdUCATION}

agement

$(J D M), 12(3)$,

http://dx.doi.org/10.4018/jdm.2001070101

[12] Messinger, J. (2012). M-learning| An exploration of the attitudes and perceptions of high school students versus teachers regarding the current and future use of mobile devices for learning (Doctoral dissertation, Pepperdine University). Online at: http://gradworks.umi.com/3487951.pdf

[13] Venkatesh, V., Morris, M., Davis, G.B. and Davis, F.D. (2003) User acceptance of information technology: Toward a unified view. Management Information System Quarterly, 27, 425-478.

[14] UNESCO (2012). Turning on Mobile Learning in Europe: Illustrative Initiatives and Policy Implications. UNESCO Working Paper Series on Mobile Learning, France.

[15] Kim, H. \& Kankanhalli, A. (2009). Investigating user resistance to information systems implementation: a status quo bias perspective. MIS Quarterly, 33, 3, 567-582.

[16] Nov, O. \& Ye, C. (2008). Users' personality and perceived ease of use of digital libraries: the case for resistance to change. Journal of the American Society for Information Science \& Technology, 59, 5, 845-851. http://dx.doi.org/10.1002/asi.20800

[17] Huang, R. T., Jang, S. J., Machtmes, K., and Deggs, D. (2012). Investigating the roles of perceived playfulness, resistance to change and self-management of learning in mobile English learning outcome. British Journal of Educational Technology, 43(6), 1004-1015. http://dx.doi.org/10.1111/j.1467-8535.2011.01239.x

[18] Loch, K., Straub, D., and Kamel, S. (2003). Diffusing the Internet in the Arab world: the role of social norms and technological culturation, IEEE Transactions on Engineering Management, 50, pp. 45-63. http://dx.doi.org/10.1109/TEM.2002.808257

[19] Al-Oteawi, S. M. (2002). The perceptions of administrators and teachers in utilizing information technology in instruction, administrative work, technology planning and staff development in Saudi Arabia (Doctoral dissertation, Ohio University).

[20] Baker, E.W., Al-Gahtani, S.S. and Hubona, G.S. (2007). The effects of gender and age on new technology implementation in a developing country: Testing the theory of planned behavior (TPB). Information Technology \& People, Vol. 20 Iss: 4, pp.352 - 375. http://dx.doi.org/10.1108/09593840710839798

[21] Davis, F.D., Bagozzi, R.P. and Warshaw, P.R. (1989) User acceptance of computer technology-a comparison of two theoretical models. Management science, 35(8). http://dx.doi.org/10.1287/mnsc.35.8.982

[22] Cohen, L., Manion, L and Morrison, K. (2011) Research methods in education ( 7 th ed). London: Routledge.
[23] Kopcha, T. J. (2010). A systems-based approach to technology integration using mentoring and communities of practice. Educational Technology Research \& Development, 58, 2, 175-190. http://dx.doi.org/10.1007/s11423-008-9095-4

[24] Cruz, Y., Boughzala, I. and Assar, S. (2012). Opportunities and obstacles for mobile learning in a Business School. In International Conference on Communications and Information Technology (ICCIT), June 2012, 58-61. http://dx.doi.org/10.1109/ICCITechnol.2012.6285824

[25] Al-Kahtani, N.K.M., Ryan, J.J.C.H., and Jefferson, T.I. (2006). How Saudi female faculty perceive internet technology usage and potential. Information, Knowledge, Systems Management, Volume 5, Number 4, 227-243.

[26] Al-Gahtani, S.S., Hubona, G.S. and Wang, J. (2007). Information technology (IT) in Saudi Arabia: culture and the acceptance and use of IT. Information and Management, 44 (8), 681-691. http://dx.doi.org/10.1016/j.im.2007.09.002

\section{AUTHOR}

L.A. Alfarani is with King Abdulaziz University, Jeddah, Saudi Arabia and University of Leeds, Leeds, UK.

Submitted 27 January 2015. Published as resubmitted by the author 23 March 2015.

\section{APPENDIX A: THE ITEMS OF THE THREE FACTORS}

\begin{tabular}{|l|l|}
\hline \multicolumn{1}{|c|}{$\begin{array}{c}\text { The con- } \\
\text { structs }\end{array}$} & \multicolumn{1}{c|}{ The items of each construct } \\
\hline $\begin{array}{l}\text { Resistance to } \\
\text { Change (RC) }\end{array}$ & $\begin{array}{l}\text { RC1: Blending traditional teaching methods (teacher- } \\
\text { centered learning) with mobile technology in the } \\
\text { educational environment is urgently needed in order } \\
\text { to improve the quality of my teaching performance. } \\
\text { RC2: Blending traditional teaching methods (teacher- } \\
\text { centered learning) with mobile technology in the } \\
\text { educational environment is urgently needed in order } \\
\text { to improve my students' learning. } \\
\text { RC3: The use of traditional teaching methods (teach- } \\
\text { er-centered learning) is insufficient for learners in the } \\
\text { digital age. } \\
\text { RC4: Faculty members' clinging to traditional ways } \\
\text { of teaching (teacher-centered learning) is one of the } \\
\text { obstacles to the integration of mobile learning. }\end{array}$ \\
\hline
\end{tabular}

